\title{
Green Fabrication of Silver Nanoparticles by Gum Tragacanth (Astragalus gummifer): A Dual Functional Reductant and Stabilizer
}

\author{
Aruna Jyothi Kora and Jayaraman Arunachalam \\ National Centre for Compositional Characterisation of Materials (NCCCM), Bhabha Atomic Research Centre, \\ ECIL (PO), Hyderabad 500 062, India \\ Correspondence should be addressed to Jayaraman Arunachalam, aruncccm@gmail.com
}

Received 5 March 2012; Accepted 13 April 2012

Academic Editor: Edward Andrew Payzant

Copyright (C 2012 A. J. Kora and J. Arunachalam. This is an open access article distributed under the Creative Commons Attribution License, which permits unrestricted use, distribution, and reproduction in any medium, provided the original work is properly cited.

\begin{abstract}
A simple and ecofriendly procedure have been devised for the green synthesis of silver nanoparticles using the aqueous extract of gum tragacanth (Astragalus gummifer), a renewable, nontoxic natural phyto-exudate. The water soluble components in the gum act as reductants and stabilizers. The generated nanoparticles were analyzed using UV-visible spectroscopy, transmission electron microscopy, X-ray diffraction, Fourier transform-infrared spectroscopy, and Raman spectroscopy. The role of gum concentration and reaction time on the synthesis of nanoparticles was studied. By regulating the reaction conditions, spherical nanoparticles of $13.1 \pm 1.0 \mathrm{~nm}$ size were produced. Also, the possible functional groups involved in reduction and capping of nanoparticles has been elucidated. The antibacterial activity of the fabricated nanoparticles was tested on model Gram-negative and Gram-positive bacterial strains with well-diffusion method. These nanoparticles exhibited considerable antibacterial activity on both the Gram classes of bacteria, implying their potential biomedical applications.
\end{abstract}

\section{Introduction}

Gum tragacanth is a naturally occurring complex, acidic polysaccharide derived as an exudate from the bark of Astragalus gummifer (Fabaceae family), a native tree of western Asia. Mostly, it is commercially produced in Iran and Turkey. The name tragacanth is originated from the Greek words tragos (goat) and akantha (thorn), indicating the curved shape of the gum [1]. This biopolymer is an arabinogalactan type of natural gum and its structural, physicochemical, compositional, solution, thermal, rheological and emulsifying properties have been well characterized and studied [28].This biopolymer is a high-arabinose, protein containing, acidic heteropolysaccharide, which occurs in nature as mixed calcium, magnesium, and sodium salts. It has a molecular weight of $\sim 8.4 \times 10^{5} \mathrm{~g} / \mathrm{mol}$. This natural polymer consists of a mixture of water-soluble (tragacanthin) and water-swellable (bassorin) polysaccharide fractions [1, 3].
The water soluble tragacanthin constitutes around 30-40\% of the gum, and it is a neutral, highly branched, type II arabinogalactan comprising $(1 \rightarrow 6)$ - and $(1 \rightarrow 3)$-linked core chain containing galactose and arabinose and side groups of $(1 \rightarrow 2)-,(1 \rightarrow 3)-$, and $(1 \rightarrow 5)$-linked arabinose units occurring as monosaccharide or oligosaccharides. The primary structure of tragacanthin is composed of sugars such as, L-fucose, L-arabinose, D-xylose, D-mannose, Dgalactose and D-glucose in a molar ratio of 3:52:29:6:5: 5 $[1,2]$.

The gum tragacanth with a CAS number 9000-65-1 is considered as "generally recognized as safe" (GRAS) and approved as a food ingredient (21CFR184.1351) by the Food and Drug Administration, USA under the function of emulsifier, stabilizer, and thickener. It is also approved as a food additive within the class of thickeners, stabilizers, emulsifiers, and gelling agents in European Union and has been accorded with E413, a European food safety E number [1]. It is 
considered as a food grade additive by the Bureau of Indian Standards, India under Indian Standard IS 7238: 1997 [9]. Several studies have established that gum tragacanth is nontoxic, nonmutagenic, nonteratogenic, noncarcinogenic and has a potential application as a food additive [10-13], dressing bandage for burn healing [14], immobilizing agent in viral plaque assay [15], superabsorbent hydrogel [16] and carrier for controlled release of verapamil hydrochloride, a water-soluble drug [17]. It is also employed as an administration vehicle for insecticide [18], antidepressant [19], and antilipemic agents [20]. In addition, investigations carried out with tragacanth fed rats and white leghorn cockerels have established the hypolipidemic activity of this gum [21, 22]. This hydrocolloid is resistant to gastrointestinal enzymes and known to be degraded enzymatically only by the specific microflora of the colon such as Bifidobacterium longum, thereby aiding in bifidus fermentation [23-25]. Thus, it functions as a soluble dietary fiber, accelerates the digesta passage, and acts as a laxative [26].

The attractive features of gum tragacanth prompted us to use this biopolymer for the synthesis and stabilization of silver nanoparticles due to its (i) nontoxic nature and GRAS; (ii) natural availability; (iii) greater resistance to microbial attacks and long shelf-life $[1,10,12]$. The green synthesis of silver nanoparticles relies on the implementation of the basic requirements of green chemistry $[27,28]$. In this perspective, we have devised a simple and green synthetic way for the production of silver nanoparticles using a renewable, biodegradable natural plant polymer, gum tragacanth as both the reducing and stabilizing agent. The synthesis was carried out in an aqueous medium by autoclaving to produce sterile silver nanoparticle, free from microbes. The present study focuses on the production, characterization, capping and stabilization of silver nanoparticles. We have also established the antibacterial activity of the fabricated nanoparticles on Gram-positive and Gram-negative bacteria for their potential biomedical applications.

\section{Materials and Methods}

2.1. Synthesis of Silver Nanoparticles. Silver nitrate $\left(\mathrm{AgNO}_{3}\right)$ (E. Merck, Mumbai, India) of analytical reagent grade was used for the synthesis. "Gum tragacanth," 99\% was purchased from Loba Chemie, Mumbai, India. All the solutions were prepared in ultra pure water. A $0.5 \%(\mathrm{w} / \mathrm{v})$ of homogenous gum stock solution was prepared by adding this powder to a reagent bottle containing ultra pure water and stirring overnight at room temperature. Then, this solution was centrifuged $(5500 \times \mathrm{g}, 10 \mathrm{~min})$ to remove the insoluble materials, and the supernatant was used for all the experiments. The protein concentration in the aqueous extract was quantified by Lowry's method using a Bangalore Genei protein estimation kit, Cat number 105560 (Bangalore, India). The silver nanoparticles were synthesized by autoclaving the silver nitrate solutions containing various concentrations of gum extract at $121^{\circ} \mathrm{C}$ and 15 psi for different durations of time. The effect of concentration of gum and reaction time on nanoparticle synthesis was studied.
2.2. Characterization of Synthesized Silver Nanoparticles. In order to study the formation of silver nanoparticles, the UVvisible absorption spectra of the prepared colloidal solutions were recorded using an Elico SL 196 spectrophotometer (Hyderabad, India), from 250 to $800 \mathrm{~nm}$, against autoclaved gum blank. The absorption spectra of gum before and after autoclaving were also recorded against ultra pure water blank. The size and shape of the nanoparticles were obtained with Hitachi H 7500 (Tokyo, Japan); JEOL 3010 and JEOL 2100 (Tokyo, Japan) coupled to Oxford Instruments Energy Dispersive X-ray (EDX) (High Wycombe, UK) transmission electron microscopes, operating at 80 and $200 \mathrm{kV}$, respectively. The samples were prepared by depositing a drop of colloidal solution on a carbon-coated copper grid and drying at room temperature. The nanoparticles were recovered from the synthesized solutions by centrifugation and made into powders using a FTS Systems, Dura-DryTM MP freeze dryer (NY, USA). The X-ray diffraction analysis was conducted with a Rigaku, Ultima IV diffractometer (Tokyo, Japan) using monochromatic $\mathrm{Cu} K \alpha$ radiation $(\lambda=1.5406 \AA)$ running at $40 \mathrm{kV}$ and $30 \mathrm{~mA}$. The intensity data for the lyophilized nanosilver powder was collected over a $2 \theta$ range of $35-85^{\circ}$ with a scan rate of $1^{\circ} / \mathrm{min}$. The IR spectra of the lyophilized samples were recorded using a Bruker Optics, TENSOR 27 FTIR spectrometer (Ettlingen, Germany); over a spectral range of $400-4000 \mathrm{~cm}^{-1}$. The Raman spectrum of the synthesized nanoparticles was recorded at room temperature using the $532 \mathrm{~nm}$ line from a SUWTECH, G-SLM diode laser (Shanghai, China). The scattered light was collected and detected using a CCD-based monochromator, covering a spectral range of $150-1700 \mathrm{~cm}^{-1}$. The sample solution was taken in a standard $1 \mathrm{~cm} \times 1 \mathrm{~cm}$ cuvette and placed in the path of the laser beam.

2.3. Antibacterial Assay. The well-diffusion method was used to study the antibacterial activity of the synthesized silver nanoparticles. All the glassware, media, and reagents used were sterilized in an autoclave at $121^{\circ} \mathrm{C}$ for $20 \mathrm{~min}$. Staphylococcus aureus (ATCC 25923); and Escherichia coli (ATCC 25922), E. coli (ATCC 35218) and Pseudomonas aeruginosa (ATCC 27853) were used as model test strains for Grampositive and Gram-negative bacteria, respectively. Bacterial suspension was prepared by growing a single colony overnight in nutrient broth and by adjusting the turbidity to 0.5 McFarland standard. Mueller Hinton agar [29] plates were inoculated with this bacterial suspension, and $5 \mu \mathrm{g}$ of silver nanoparticles were added to the center well with a diameter of $6 \mathrm{~mm}$. The nanoparticles used here were prepared with $0.1 \%$ gum solution containing $1 \mathrm{mM} \mathrm{AgNO}_{3}$, autoclaved for $30 \mathrm{~min}$. Negative control plates were maintained with wells loaded with autoclaved gum. Culture plates loaded with discs of antibiotic, erythromycin $(15 \mu \mathrm{g} /$ disc $)$ were included as positive controls. These plates were incubated at $37^{\circ} \mathrm{C}$ for $24 \mathrm{~h}$ in a bacteriological incubator, and the zone of inhibition (ZOI) was measured by subtracting the well/disc diameter from the total inhibition zone diameter. Three independent experiments were carried out with each bacterial strain. 


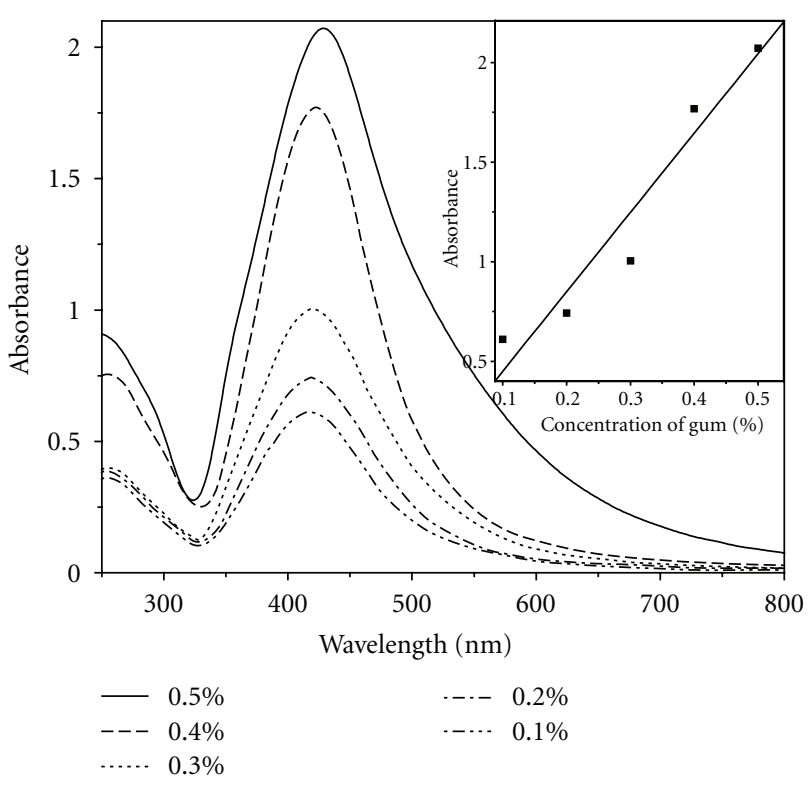

FIGURE 1: The UV-vis absorption spectra of silver nanoparticles synthesized by autoclaving different concentrations of gum extract at $1 \mathrm{mM} \mathrm{AgNO}_{3}$ concentration for $30 \mathrm{~min}$; inset plot of $A_{\max }$ versus gum concentration.

\section{Results and Discussion}

3.1. UV-visible Spectroscopy (UV-vis). The formation of silver nanoparticles was recorded by measuring the absorption spectra of synthesized silver nanoparticles against respective autoclaved gum blanks. The role of gum concentration on the synthesis was studied by autoclaving the different concentrations $(0.1-0.5 \%)$ of gum solutions containing $1 \mathrm{mM}$ of silver nitrate for $30 \mathrm{~min}$ (Figure 1). After autoclaving the silver nitrate containing gum solutions, the appearance of yellow colour in the reaction mixtures was observed. This is a clear indication for the formation of silver nanoparticles by the gum. In the UV-vis spectra strong peaks with maxima around $418-429 \mathrm{~nm}$ were observed, which correspond to the typical surface plasmon resonance (SPR) of conducting electrons from the surface of silver nanoparticles. With an increase in gum concentration, there is an enhancement in the nanoparticle synthesis. In addition, the SPR band broadened with a red shift from 418 to $429 \mathrm{~nm}$, indicating an increase in particle size. The synthesis was also evaluated by varying the reaction time (20-60 $\mathrm{min}$ ), and reduction was studied with $0.1 \%$ gum at $1 \mathrm{mM} \mathrm{AgNO}_{3}$ (Figure 2). It was noticed that the intensity of the absorption increased with time with no significant difference in peak position or shift in SPR $(418 \mathrm{~nm})$, signifying a continuous reduction of the silver ions. This also shows the large reduction capability of the gum.

3.2. Transmission Electron Microscopy. Figure 3 shows the TEM images of the silver nanoparticles synthesized with $0.1 \%$ gum and $1 \mathrm{mM} \mathrm{AgNO}_{3}$, autoclaved for $30 \mathrm{~min}$. It was noticed that the nanoparticles are spherical in shape and nearly monodispersed in nature. The size of the particles

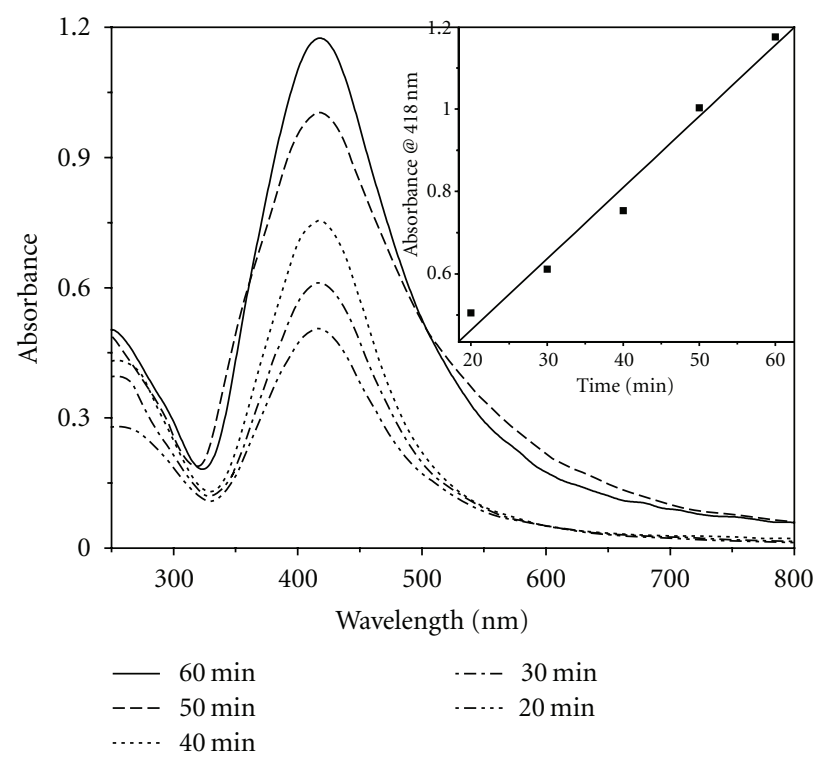

Figure 2: The UV-vis absorption spectra of silver nanoparticles

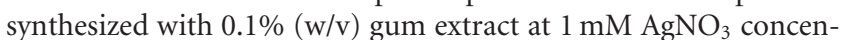
tration for different durations of autoclaving; inset plot of $A_{\max }$ versus autoclaving time.

ranged from $11.4-14.7 \mathrm{~nm}$, and the average particle size obtained from the corresponding diameter distribution was about $13.1 \pm 1.0 \mathrm{~nm}$ (Figure 3(f)). The selected-area electron diffraction (SAED) pattern depicted in Figure 3(e) exhibits concentric rings with intermittent bright dots, indicating that these nanoparticles are highly crystalline in nature. These rings can be attributed to the diffraction from the (111), (200), (220), and (311) planes of face-centered cubic (fcc) silver. The crystallinity of the synthesized nanoparticles was also supported from the observed clear lattice fringes in high-resolution image (Figure 3(d)). When the concentration of gum was increased from 0.1 to $0.5 \%$ at $1 \mathrm{mM}$ $\mathrm{AgNO}_{3}$ and $30 \mathrm{~min}$ of autoclaving, the particle size of the formed nanoparticles increased (Table 1). These nanoparticles are spherical; polydisperse with sizes from $6.0-90.9 \mathrm{~nm}$, and the average particle size was about $24.3 \pm 17.9 \mathrm{~nm}$. The increase in average particle size and polydispersity with increase in concentration of the gum was also evident from the broadening and red shift in SPR band of UV-vis spectra (Figure 1). While at $0.1 \%$ gum and $1 \mathrm{mM} \mathrm{AgNO}$ concentration; with an increase in reaction time from 30 to $60 \mathrm{~min}$ the size of the spherical particles ranged from 9.3$48.0 \mathrm{~nm}$. The average particle size was about $28.7 \pm 12.4 \mathrm{~nm}$ (Table 1). Based on these results, it can be concluded that the particle size of the nanoparticles can be controlled by varying the gum concentration and reaction time.

3.3. X-Ray Diffraction. The XRD technique was used to determine and confirm the crystal structure of silver nanoparticles. There were five well-defined characteristic diffraction peaks at $38.3^{\circ}, 44.5^{\circ}, 64.7^{\circ}, 77.6^{\circ}$, and $81.8^{\circ}$ respectively, corresponding to (111), (200), (220), (311), 


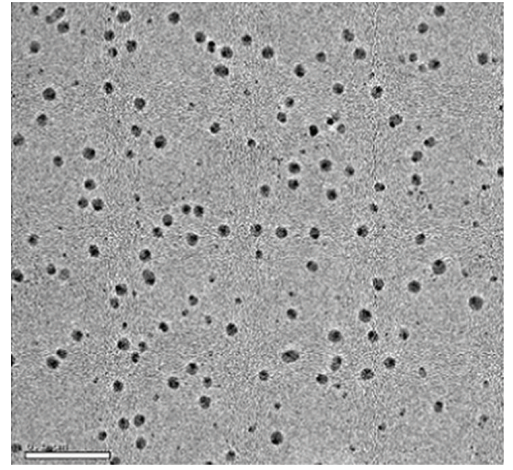

(a)

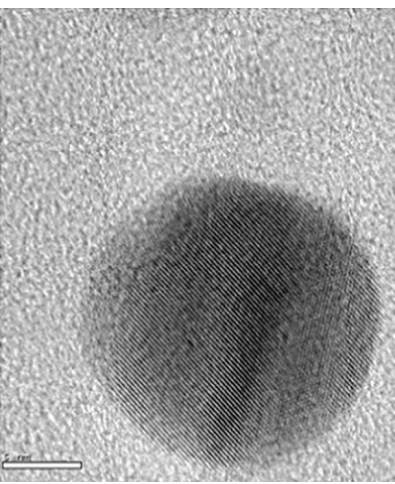

(d)

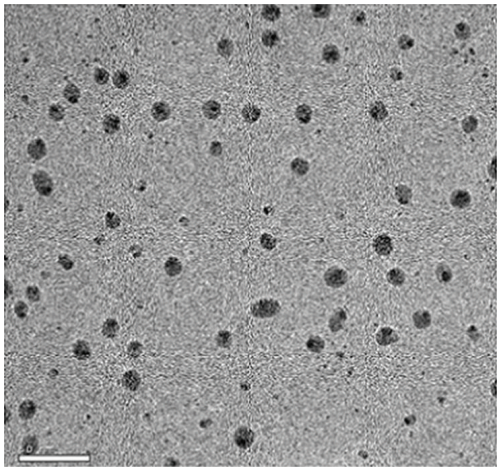

(b)

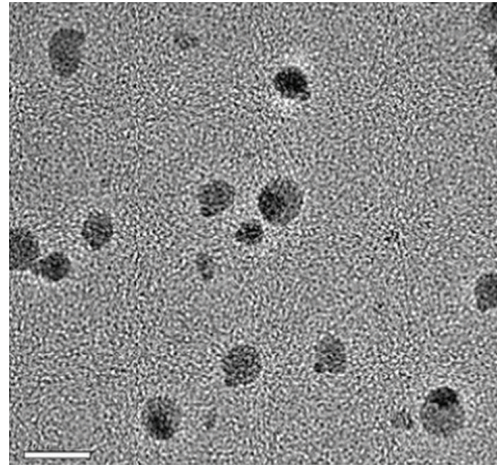

(c)

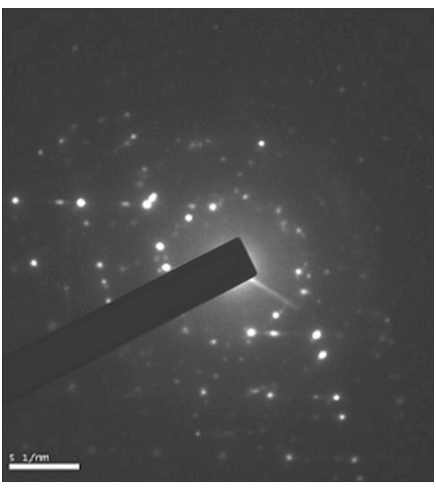

(e)

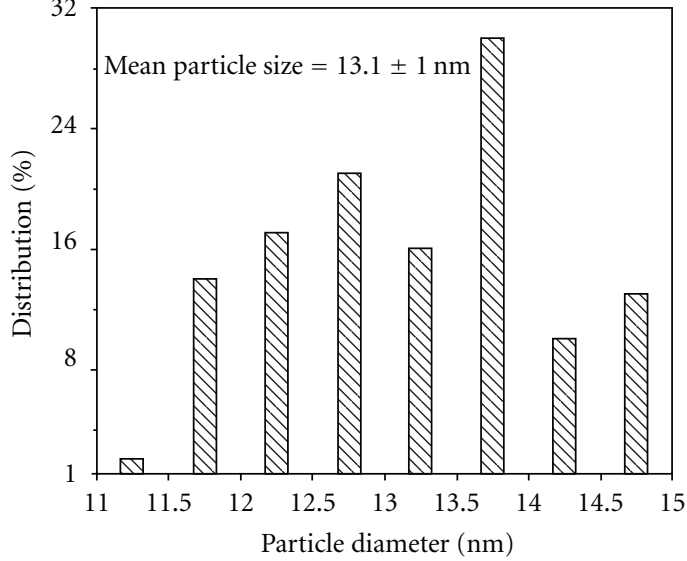

(f)

FIgURE 3: TEM images of silver nanoparticles synthesized with $0.1 \%$ (w/v) gum and $1 \mathrm{mM} \mathrm{AgNO}$, autoclaved for $30 \mathrm{~min}$, at (a) $100 \mathrm{~nm}$, (b) $50 \mathrm{~nm}$, (c) $20 \mathrm{~nm}$, and (d) $5 \mathrm{~nm}$ scale.(e) corresponding SAED pattern and (f) histogram showing the particle size distribution.

TABle 1: Particle diameter distribution and average particle sizes obtained at different reaction conditions of silver nanoparticle synthesis.

\begin{tabular}{lcc}
\hline Reaction condition & $\begin{array}{c}\text { Particle range } \\
(\mathrm{nm})\end{array}$ & $\begin{array}{c}\text { Average } \\
\text { particle size } \\
(\mathrm{nm})\end{array}$ \\
\hline $0.1 \%$ gum, $1 \mathrm{mM} \mathrm{AgNO}_{3}, 30 \mathrm{~min}$ & $11.4-14.7$ & $13.1 \pm 1.0$ \\
$0.5 \%$ gum, $1 \mathrm{mM} \mathrm{AgNO}_{3}, 30 \mathrm{~min}$ & $13.0-90.9$ & $24.3 \pm 17.9$ \\
$0.1 \%$ gum, $1 \mathrm{mM} \mathrm{AgNO}_{3}, 60 \mathrm{~min}$ & $15.0-48.0$ & $28.7 \pm 12.4$ \\
\hline
\end{tabular}

and (222) planes of face-centered cubic (fcc) crystal structure of metallic silver (Figure 4). The interplanar spacing $\left(d_{\mathrm{h} \mathrm{k} \mathrm{l}}\right)$ values $(2.348,2.034,1.439,1.229$, and $1.176 \AA)$ calculated from the XRD spectrum of silver nanoparticles is in agreement with the standard silver values. Thus, the XRD pattern, further corroborating the highly crystalline nature of nanoparticles observed from SAED pattern and high-resolution TEM image (Figure 3). The lattice constant calculated from this pattern was $4.070 \AA$, a value which is in agreement with the value reported in literature for silver (JCPDS PDF04-0783). Also, the broadening of the diffraction peaks was observed owing to the effect of nanosized particles. The intensity of the (111) peak was much higher than the other diffractions. It is important to note that the ratio of the intensity between (200) and (111) peaks is lower than the standard value $(0.24$ versus 0.4$)$ and also the ratio of (220) and (111) peaks is lower than the standard value $(0.15$ versus 0.25$)$. These results clearly demonstrate that the (111) lattice plane is the preferred orientation for these silver nanoparticles. These findings are in concurrence with the observations reported by other researchers [30].

3.4. Fourier Transform-Infrared Spectroscopy (FTIR). The FTIR spectra were recorded for lyophilized gum extract and nanoparticles to detect the functional groups of gum involved in the reduction of silver ions (Figure 5). The major absorbance bands present in the spectrum of gum were at 3435, 2926, 2856, 2150, 1740, 1626, 1429, 1379, $1258,1153,1076$, and $1040 \mathrm{~cm}^{-1}$, respectively. The broad band observed at $3435 \mathrm{~cm}^{-1}$ could be assigned to stretching vibrations of $\mathrm{O}-\mathrm{H}$ groups in the gum. The bands at 2926 and $2856 \mathrm{~cm}^{-1}$ correspond to asymmetric and symmetric stretching vibrations of methylene groups, respectively. The broad band at $2150 \mathrm{~cm}^{-1}$ arises from various carbonyl species of the gum. The sharp peak at $1740 \mathrm{~cm}^{-1}$ could be assigned to carbonyl stretching vibrations in aldehydes, ketones and carboxylic acids. The stronger band found at 


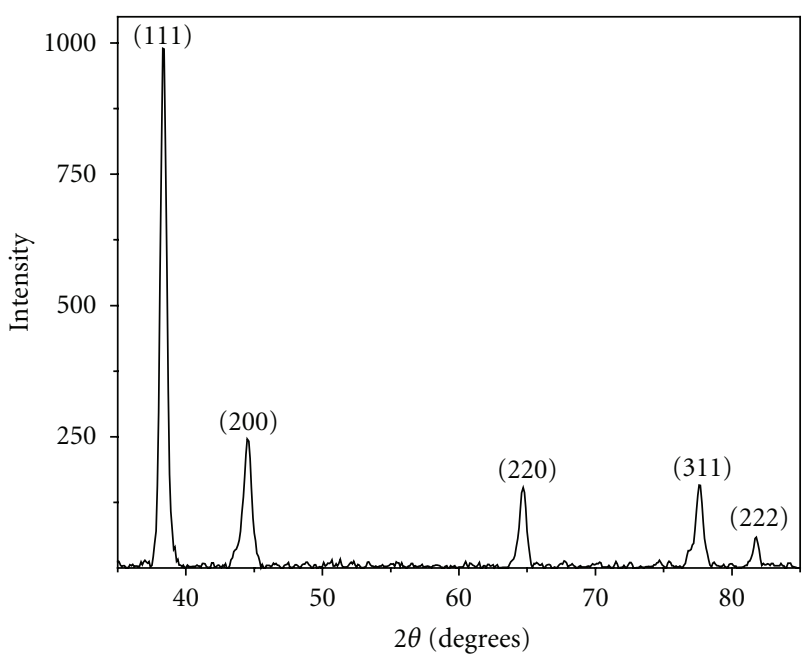

Figure 4: X-ray diffraction pattern of lyophilized silver nanoparticles, indicating face-centered cubic (fcc) crystal structure.

$1626 \mathrm{~cm}^{-1}$ could be assigned to characteristic asymmetrical stretch of carboxylate group. The symmetrical stretch of carboxylate group can be attributed to the bands present at 1429 and $1379 \mathrm{~cm}^{-1}$. The peaks at 1258 and 1153; 1076 and $1040 \mathrm{~cm}^{-1}$ were due to the $\mathrm{C}-\mathrm{O}$ stretching vibrations of polyols, ether and alcoholic groups, respectively. While, the spectrum of lyophilized nanoparticles showed characteristic absorbance bands at 3435, 2922, 2856, 2071, 1726, 1630, $1452,1375,1261,1163$, and $1028 \mathrm{~cm}^{-1}$, respectively. In the IR spectrum of nanoparticles, small (1626 to $1630 \mathrm{~cm}^{-1}$ and 1379 to $1375 \mathrm{~cm}^{-1}$ ) and large (1429 to $1452 \mathrm{~cm}^{-1}$ ) shifts in the absorbance peaks with decreased band intensity were observed, suggesting the binding of silver ions with carboxylate groups of the gum [31]. It is pertinent to note that the nanoparticles show a large band shift corresponding to various carbonyl groups (2150 to 2071 and 1740 to $1726 \mathrm{~cm}^{-1}$ ) in the FTIR spectra. In addition, a shift in the polyols (1258 to $1261 \mathrm{~cm}^{-1}$ and 1153 to $1163 \mathrm{~cm}^{-1}$ ) and alcoholic groups ( 1040 to $1028 \mathrm{~cm}^{-1}$ ) was also observed. This confirms that the reduction of the silver ions is coupled to the oxidation of the hydroxyl and carbonyl groups. Based on these band shifts, it can be inferred that both hydroxyl and carbonyl groups of gum are involved in the synthesis of silver nanoparticles [30].

3.5. Raman Spectroscopy. In order to find out the possible functional groups of capping agents associated in the stabilization of silver nanoparticles, Raman spectrum of the nanoparticles was recorded (Figure 6). The spectrum shows a sharp band at $240 \mathrm{~cm}^{-1}$, attributed to the stretching vibrations of $\mathrm{Ag}-\mathrm{N}[32,33]$ and $\mathrm{Ag}-\mathrm{O}$ bonds $[34,35]$. This peak indicates the formation of a chemical bond between silver and amino nitrogen [33]; and silver and carboxylate groups $[34,35]$ of the gum molecules. It confirms that the gum is bound to the silver nanoparticle surface either through amino or carboxylate group or both [30]. The broad ones at 1365 and $1550 \mathrm{~cm}^{-1}$ correspond to symmetric and

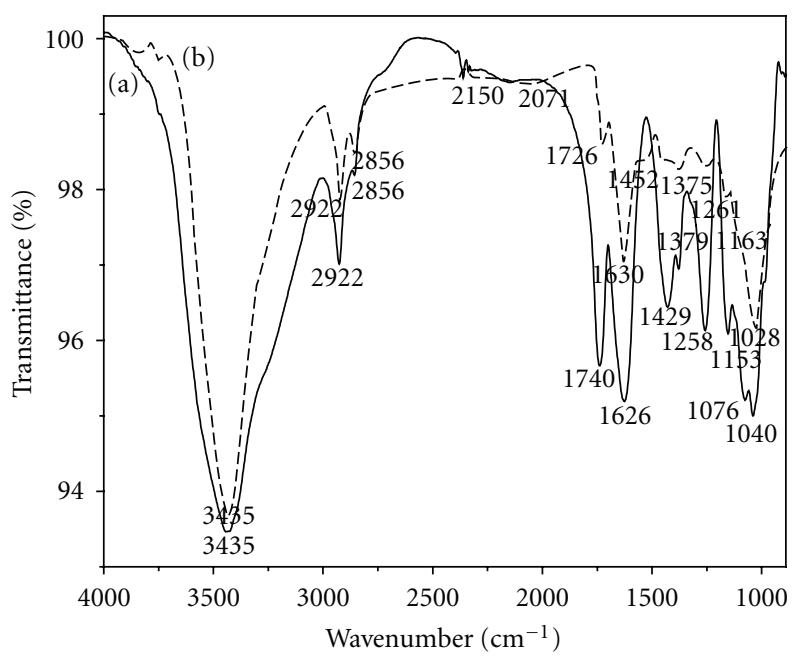

FIGURE 5: FTIR spectra of freeze dried (a) aqueous extract of gum tragacanth and (b) silver nanoparticles.

asymmetric $\mathrm{C}=\mathrm{O}$ stretching vibrations of carboxylate group, respectively [33]. The enhancement in the intensity of the $\mathrm{CO}_{2}$ stretching vibrations suggests the direct binding of the $\mathrm{COO}^{-}$group with the silver surface [34]. The peaks at 1041, 1123,1165 and $1301 \mathrm{~cm}^{-1}$; and 803 and $828 \mathrm{~cm}^{-1}$ come from the $\mathrm{C}-\mathrm{H}$ in plane bending and out of plane wag, respectively [32] from the saccharide structure of gum. The features at 465 and 496; 637 and $1444 \mathrm{~cm}^{-1}$ assigned, respectively, to the stretching vibrations of $(\mathrm{C}-\mathrm{N}-\mathrm{C}),(\mathrm{C}-$ $\mathrm{S}-\mathrm{C}$ ) and phenyl ring [35]. Thus, from the preferential enhancement of these Raman bands; it can be concluded that both amino and carboxylate groups of the gum are involved in the capping of the silver nanoparticles. These results are in concurrence with earlier biosynthesis of silver nanoparticles carried out with fungus Trichoderma asperellum [33] and gum kondagogu [30]. It was reported earlier that the carboxylate groups of glycoprotein of gum Acacia were involved in binding/stabilization of silver nanoparticles [31]. It is known that proteins can bind to nanoparticles either through free amino groups or by electrostatic interaction of negatively charged carboxylate groups [36]. The gum tragacanth is known to contain protein, and the protein content was reported to be in the range of $1.0-3.6 \%$ [1]. This observation is further substantiated by the measured protein concentration of $0.93 \%$ for the gum extract and the UV-vis absorption spectrum of the $0.5 \%$ gum extract against water blank, given in the inset of Figure 6. An absorption peak at $280 \mathrm{~nm}$ is evident and is attributed to the electronic excitations in tryptophan and tyrosine residues in the proteins [36], which are present in the gum. Thus, one can conclude that once the silver ions are reduced to silver nanoparticles by the gum, proteins present in the gum subsequently encapsulate and stabilize these particles along with saccharide molecules. Based on these observations, these silver nanoparticles can be used as a possible substrate for SERS. As observed in IR spectra (Figure 5), the gum is rich in various functional groups; their capping on silver nanoparticles provides surface reactivity. 


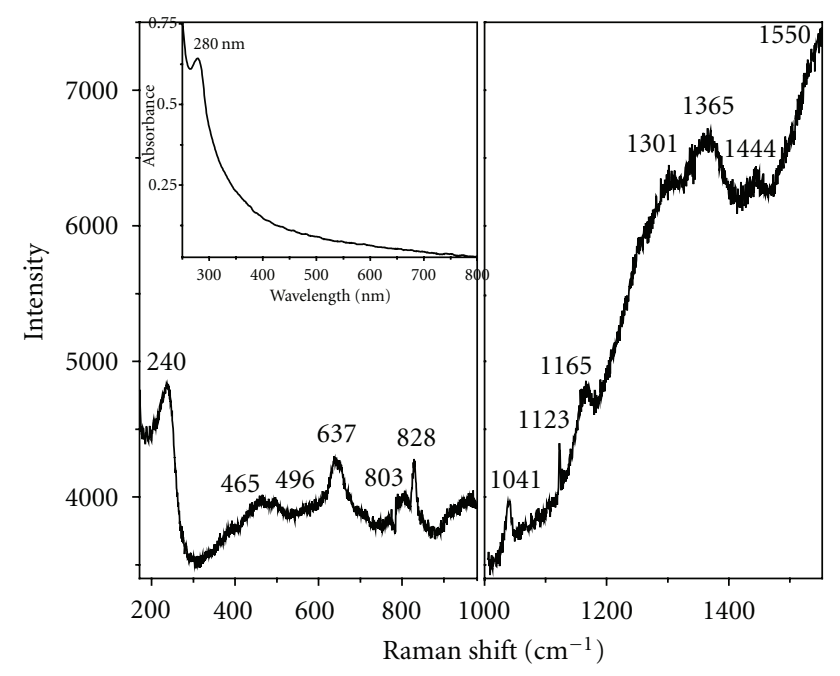

FIGURE 6: Raman spectrum of aqueous silver nanoparticle solution. Inset: the UV-vis absorption spectrum of the $0.5 \%(\mathrm{w} / \mathrm{v})$ gum extract against water blank.

TABLE 2: Inhibition zones ( $\mathrm{mm}$ ) observed with different bacterial culture plates loaded with silver nanoparticles and the antibiotic erythromycin.

\begin{tabular}{lcccc}
\hline $\begin{array}{l}\text { Test } \\
\text { compound } \\
(\mu \mathrm{g})\end{array}$ & $\begin{array}{c}\text { S. aureus } \\
25923\end{array}$ & $\begin{array}{c}\text { E. coli } \\
25922\end{array}$ & $\begin{array}{c}\text { E. coli } \\
35218\end{array}$ & $\begin{array}{c}\text { P. aeruginosa } \\
27853\end{array}$ \\
\hline $\begin{array}{l}\text { Silver } \\
\text { nanoparticles }\end{array}$ & $11.5 \pm 0.0$ & $9.5 \pm 0.4$ & $5.5 \pm 0.0$ & $10.5 \pm 0.0$ \\
$\begin{array}{l}(5) \\
\begin{array}{l}\text { Erythromycin } \\
(15)\end{array}\end{array}$ & $23.5 \pm 1.0$ & $7.0 \pm 1.1$ & $9.0 \pm 1.1$ & $11.0 \pm 1.1$ \\
\hline
\end{tabular}

3.6. Antibacterial Assay. For checking the antibacterial activity, silver nanoparticles with an average size of $13.1 \pm 1.0 \mathrm{~nm}$ were used. These nanoparticles were prepared with $0.1 \%$ gum extract containing $1 \mathrm{mM} \mathrm{AgNO}_{3}$, autoclaved for $30 \mathrm{~min}$. After $24 \mathrm{~h}$ of incubation at $37^{\circ} \mathrm{C}$, growth suppression was observed in plates loaded with $5 \mu \mathrm{g}$ of silver nanoparticles. The ZOI of around $11.5 \pm 0 \mathrm{~mm}$ was observed for the Gram-positive bacterial strain S. aureus ATCC 25923. In the case of Gram-negative bacterial strains E. coli ATCC 25922, E. coli ATCC 35218, and P. aeruginosa ATCC 27853; the detected ZOI were $9.5 \pm 0.4,5.5 \pm 0$, and $10.5 \pm 0 \mathrm{~mm}$, respectively.Whereas, the negative control plates loaded with autoclaved gum did not produce any ZOI (Figure 7). In the case of positive control plates loaded with erythromycin discs, growth inhibition was noted (Table 2). Based on these results, it can be concluded that the synthesized silver nanoparticles had significant antibacterial action on both Gram classes of bacteria.

\section{Conclusion}

By autoclaving the metal precursor silver nitrate with aqueous extract of gum tragacanth, we have produced spherical

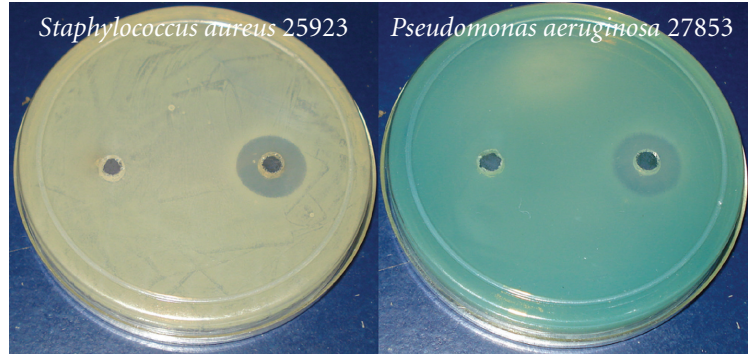

FIGURE 7: Bacterial culture plates showing the inhibition zones around the loaded wells. Left well: autoclaved gum extract and right well: $5 \mu \mathrm{g}$ of silver nanoparticles.

silver nanoparticles of around $13.1 \mathrm{~nm}$. The renewable, nontoxic components of this natural phytoexudate play dual role of reducing and stabilizing agents for the silver ions. The abundance of the gum makes this green method amenable for large-scale production of silver nanoparticles. Based on Raman spectroscopy studies, these silver nanoparticles can be used as a possible substrate for SERS. Compared to conventional antibiotics, the development of silver resistance in microbes is unlikely due to its action on broad spectrum of targets in cell. As these nanoparticles demonstrated significant antibacterial activity on both Gram classes of bacteria; they can have promising biomedical applications where antibiotic resistance is a major problem. In addition, these functionalized nanoparticles are useful for various applications such as targeted biological interactions [37], drug delivery [38], and biological labels [39].

\section{Acknowledgments}

The authors thank Dr. S.V. Narasimhan, associate director and Dr. Tulsi Mukherjee, director, Chemistry Group, BARC for their constant support and encouragement for this work. The support rendered for high-resolution TEM measurements by the DST unit on Nanoscience, Sophisticated Analytical Instrument Facility (SAIF) at IIT-Madras, Chennai, is gratefully acknowledged.

\section{References}

[1] G. O. Phillips and P. A. Williams, Handbook of Hydrocolloids, Woodhead Publishing Limited, Cambridge, UK, 2nd edition, 2009.

[2] C. A. Tischer, M. Iacomini, and P. A. J. Gorin, "Structure of the arabinogalactan from gum tragacanth (Astralagus gummifer)," Carbohydrate Research, vol. 337, no. 18, pp. 1647-1655, 2002.

[3] N. Gralén and M. Kärrholm, "The physicochemical properties of solutions of gum tragacanth," Journal of Colloid Science, vol. 5, no. 1, pp. 21-36, 1950.

[4] M. J. Zohuriaan and F. Shokrolahi, "Thermal studies on natural and modified gums," Polymer Testing, vol. 23, no. 5, pp. 575-579, 2004.

[5] F. Chenlo, R. Moreira, and C. Silva, "Rheological behaviour of aqueous systems of tragacanth and guar gums with storage time," Journal of Food Engineering, vol. 96, no. 1, pp. 107-113, 2010 . 
[6] D. M. W. Anderson and M. M. E. Bridgeman, "The composition of the proteinaceous polysaccharides exuded by Astragalus microcephalus, A. Gummifer and A. Kurdicus-the sources of turkish gum tragacanth," Phytochemistry, vol. 24, no. 10, pp. 2301-2304, 1985.

[7] D. M. W. Anderson and D. A. D. Grant, "Chemical compositions of the nitrogen containing gum tragacanth exudates from asiatic Astragalus species, grown in North America," Food Hydrocolloids, vol. 3, no. 3, pp. 217-223, 1989.

[8] D. M. W. Anderson, J. F. Howlett, and C. G. A. McNab, “The amino acid composition of the proteinaceous component of gum tragacanth (Asiatic Astragalus spp.)," Food Additives and Contaminants, vol. 2, no. 4, pp. 231-235, 1985.

[9] B. O. I. Standards, “IS 7238: 1997," Section 3, The Gazette of India, 2009.

[10] D. M. W. Anderson, "Evidence for the safety of gum tragacanth (Asiatic Astragalus spp.) and modern criteria for the evaluation of food additives," Food Additives and Contaminants, vol. 6, no. 1, pp. 1-12, 1989.

[11] D. M. W. Anderson, P. Ashby, A. Busuttil et al., "Transmission electron microscopy of heart and liver tissues from rats fed with gums arabic and tragacanth," Toxicology Letters, vol. 21, no. 1, pp. 83-89, 1984.

[12] M. A. Eastwood, W. G. Brydon, and D. M. W. Anderson, "The effects of dietary gum tragacanth in man," Toxicology Letters, vol. 21, no. 1, pp. 73-81, 1984.

[13] A. Hagiwara, P. Boonyaphiphat, M. Kawabe, H. Naito, T. Shirai, and N. Ito, "Lack of carcinogenicity of tragacanth gum in B6C3F1 mice," Food and Chemical Toxicology, vol. 30, no. 8, pp. 673-679, 1992.

[14] A. Moghbel, H. Agheli, E. Kalantari et al., "Design and formulation of tragacanth dressing bandage for burn healing with no dermal toxicity," Toxicology Letters, vol. 180, supplement 1, article S154, 2008.

[15] J. O’Mahony, M. O’Donoghue, J. G. Morgan, and C. Hill, "Rotavirus survival and stability in foods as determined by an optimised plaque assay procedure," International Journal of Food Microbiology, vol. 61, no. 2-3, pp. 177-185, 2000.

[16] F. Khoylou and F. Naimian, "Radiation synthesis of superabsorbent polyethylene oxide/tragacanth hydrogel," Radiation Physics and Chemistry, vol. 78, no. 3, pp. 195-198, 2009.

[17] M. R. Siahi, M. Barzegar-Jalali, F. Monajjemzadeh, F. Ghaffari, and S. Azarmi, "Design and evaluation of 1- and 3-layer matrices of verapamil hydrochloride for sustaining its release," AAPS PharmSciTech, vol. 6, no. 4, pp. E626-E632, 2005.

[18] C. Cambon, Y. Fernandez, M. Falzon, and S. Mitjavila, "Variations of the digestive absorption kinetics of carbaryl with the nature of the vehicle," Toxicology, vol. 22, no. 1, pp. 45-51, 1981.

[19] A. H. J. Herremans, J. A. M. van der Heyden, E. Ronken et al., "A drug discrimination procedure in the pigeon confirms the in vitro agonistic action of flesinoxan on the 5-HT1A receptor," European Neuropsychopharmacology, vol. 6, supplement 4, article S4, 1996.

[20] D. Kritchevsky, S. A. Tepper, and J. A. Story, "Influence of procetofen on lipid metabolism in normocholesteremic rats," Pharmacological Research Communications, vol. 11, no. 8, pp. 635-641, 1979.

[21] M. J. Fahrenbach, B. A. Riccardi, and W. C. Grant, "Hypocholesterolemic activity of mucilaginous polysaccharides in White Leghorn cockerels," Proceedings of the Society for Experimental Biology and Medicine, vol. 123, no. 2, pp. 321-326, 1966.
[22] S. Amer, R. Hamil, and P. Q. Siddiqui, "The hypolipidaemic effect of gum tragacanth in diet induced hyperlipidaemia in rats," Pakistan Journal of Pharmaceutical Science, vol. 12, no. 2, pp. 33-39, 1999.

[23] M. J. Hill, "Bacterial fermentation of complex carbohydrate in the human colon," European Journal of Cancer Prevention, vol. 4, no. 5, pp. 353-358, 1995.

[24] F. Crociani, A. Alessandrini, M. M. Mucci, and B. Biavati, "Degradation of complex carbohydrates by Bifidobacterium spp.", International Journal of Food Microbiology, vol. 24, no. 1-2, pp. 199-210, 1994.

[25] A. A. Salyers, S. E. H. West, J. R. Vercellotti, and T. D. Wilkins, "Fermentation of mucins and plant polysaccharides by anaerobic bacteria from the human colon," Applied and Environmental Microbiology, vol. 34, no. 5, pp. 529-533, 1977.

[26] A. K. Verma and R. Banerjee, "Dietary fibre as functional ingredient in meat products: a novel approach for healthy living-a review," Journal of Food Science and Technology, vol. 47, no. 3, pp. 247-257, 2010.

[27] P. Raveendran, J. Fu, and S. L. Wallen, "Completely "green" synthesis and stabilization of metal nanoparticles," Journal of the American Chemical Society, vol. 125, no. 46, pp. 1394013941, 2003.

[28] N. Vigneshwaran, R. P. Nachane, R. H. Balasubramanya, and P. V. Varadarajan, "A novel one-pot "green" synthesis of stable silver nanoparticles using soluble starch," Carbohydrate Research, vol. 341, no. 12, pp. 2012-2018, 2006.

[29] L. R. Jaidev and G. Narasimha, "Fungal mediated biosynthesis of silver nanoparticles, characterization and antimicrobial activity," Colloids and Surfaces B, vol. 81, no. 2, pp. 430-433, 2010.

[30] A. J. Kora, R. B. Sashidhar, and J. Arunachalam, "Gum kondagogu (Cochlospermum gossypium): a template for the green synthesis and stabilization of silver nanoparticles with antibacterial application," Carbohydrate Polymers, vol. 82, no. 3, pp. 670-679, 2010.

[31] Y. M. Mohan, K. M. Raju, K. Sambasivudu, S. Singh, and B. Sreedhar, "Preparation of acacia-stabilized silver nanoparticles: a green approach," Journal of Applied Polymer Science, vol. 106, no. 5, pp. 3375-3381, 2007.

[32] J. Chowdhury and M. Ghosh, "Concentration-dependent surface-enhanced Raman scattering of 2-benzoylpyridine adsorbed on colloidal silver particles," Journal of Colloid and Interface Science, vol. 277, no. 1, pp. 121-127, 2004.

[33] P. Mukherjee, M. Roy, B. P. Mandal et al., "Green synthesis of highly stabilized nanocrystalline silver particles by a non-pathogenic and agriculturally important fungus T. asperellum," Nanotechnology, vol. 19, no. 7, Article ID 075103, 2008.

[34] N. Biswas, S. Kapoor, H. S. Mahal, and T. Mukherjee, "Adsorption of CGA on colloidal silver particles: DFT and SERS study," Chemical Physics Letters, vol. 444, no. 4-6, pp. 338-345, 2007.

[35] X. Hou and Y. Fang, "Investigation of p-hydroxybenzoic acid from a new surface-enhanced Raman scattering system," Journal of Colloid and Interface Science, vol. 316, no. 1, pp. 19-24, 2007.

[36] N. Vigneshwaran, N. M. Ashtaputre, P. V. Varadarajan, R. P. Nachane, K. M. Paralikar, and R. H. Balasubramanya, "Biological synthesis of silver nanoparticles using the fungus Aspergillus flavus," Materials Letters, vol. 61, no. 6, pp. 14131418, 2007.

[37] G. M. Fent, S. W. Casteel, D. Y. Kim et al., "Biodistribution of maltose and gum arabic hybrid gold nanoparticles after intravenous injection in juvenile swine," Nanomedicine, vol. 5, no. 2, pp. 128-135, 2009. 
[38] S. Dhar, E. M. Reddy, A. Shiras, V. Pokharkar, and B. L. V. Prasad, "Natural gum reduced/stabilized gold nanoparticles for drug delivery formulations," Chemistry A, vol. 14, no. 33, pp. 10244-10250, 2008.

[39] A. M. Schrand, L. K. Braydich-Stolle, J. J. Schlager, L. Dai, and S. M. Hussain, "Can silver nanoparticles be useful as potential biological labels?” Nanotechnology, vol. 19, no. 23, Article ID 235104, 2008. 

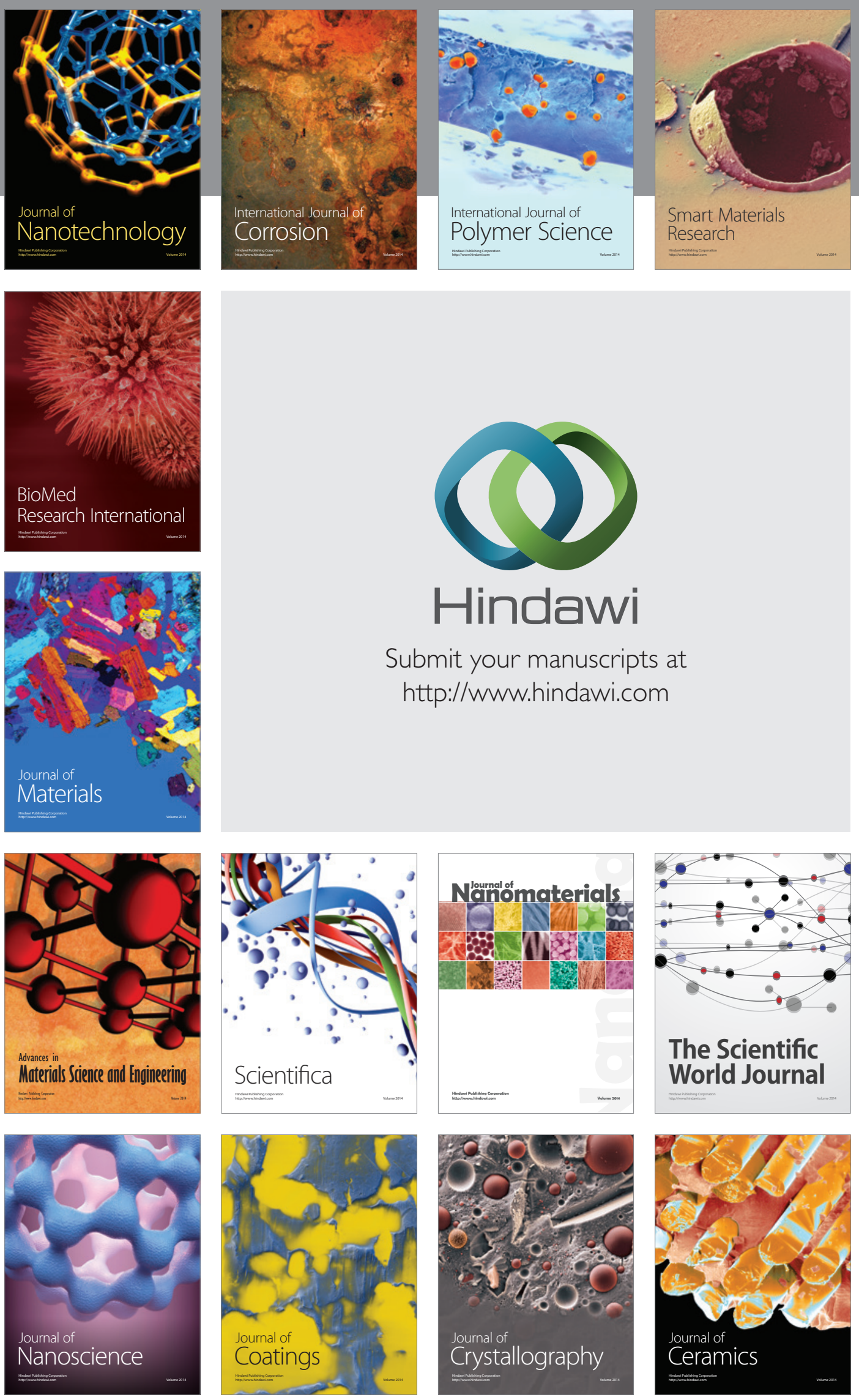

The Scientific World Journal

Submit your manuscripts at

http://www.hindawi.com

\section{World Journal}

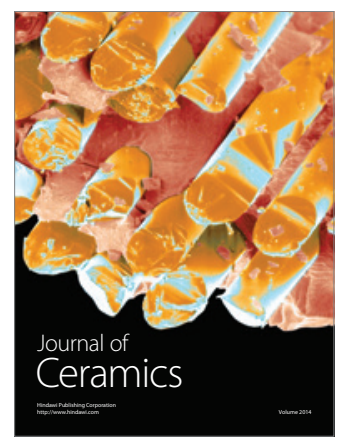

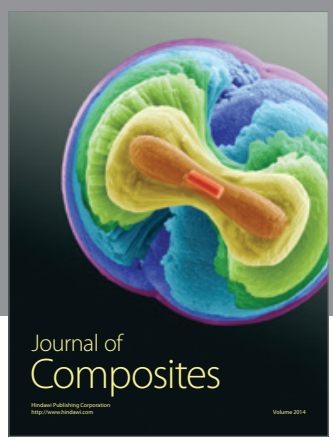
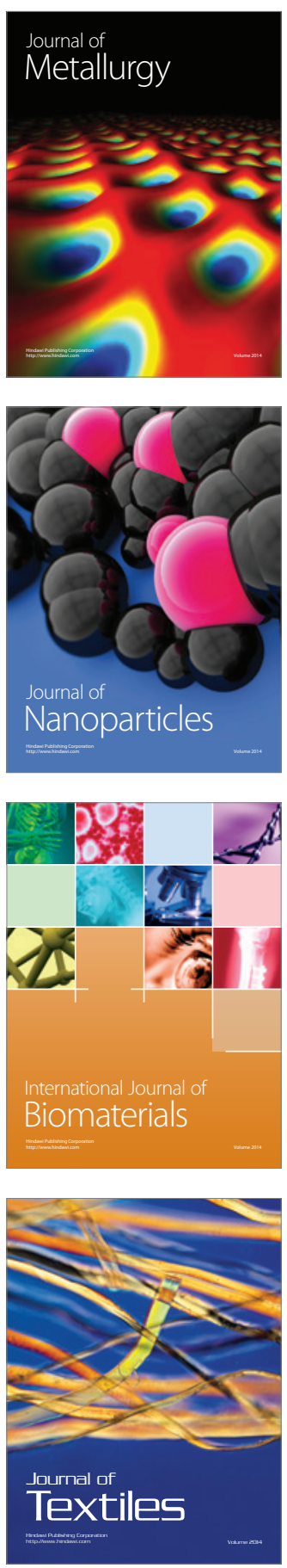